Article

\title{
Influence of Drivetrain Hybridization on Transmission Lifetime
}

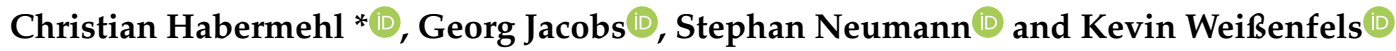 \\ Institute for Machine Elements and Systems Engineering, RWTH Aachen University, Schinkelstraße 10, \\ 52062 Aachen, Germany; georg.jacobs@imse.rwth-aachen.de (G.J.); \\ stephan.neumann@imse.rwth-aachen.de (S.N.); kevin.weissenfels@rwth-aachen.de (K.W.) \\ * Correspondence: christian.habermehl@imse.rwth-aachen.de; Tel.: +49-241-80-95606
}

Received: 21 September 2020; Accepted: 9 October 2020; Published: 12 October 2020

\begin{abstract}
Parallel hybrid drivetrains for passenger cars have additional electric drives compared to conventional drivetrains. In the event of vehicle deceleration, the electric drives are operated as generators, thus recovering kinetic energy through regeneration. If these drives are positioned upstream of the transmission input, regeneration power must be transferred by the transmission. This creates additional loads on the individual machine elements, which has a negative effect on the transmission lifetime. This paper investigates the influence of hybridization in terms of regeneration on the lifetime of bearings as highly critical elements in a dual clutch transmission. The vehicle simulation model employed in this study consists of an internal combustion engine, an electric motor, a mechanical drivetrain and the vehicle body, as well as a driver and a simple operating strategy. In this model, a detailed transmission model including its controls is embedded to determine its component loads. The resulting load spectra are used in a methodical approach to calculate the bearing lifetime of the transmission. The results show that the additional regenerative power flow reduces the bearing lifetime so that additional loads must be taken into account in the development and operation of transmission systems.
\end{abstract}

Keywords: dual-clutch transmission; bearing lifetime; vehicle simulation; hybrid electric vehicle; fatigue damage; regeneration

\section{Introduction}

Hybrid and battery electric vehicles are paving the way to the reduction of the greenhouse gas and pollutant emissions in global individual transport. Purely battery electric vehicles (BEVs) still have the disadvantages of high battery costs and low range [1]. As a transitional technology, hybrid electric vehicles (HEVs) offer a compromise between low pollutant emissions from BEVs and the high range of conventional vehicles [2]. In principle, they have the potential to be operated more efficiently than purely combustion engine vehicles. In fact, HEVs dominate the European vehicle market, with a market share of $3.7 \%$ compared to BEVs with $1 \%$ [3].

In HEVs, one or more electrical motors (EMs) can be arranged in the drivetrain and thus define different drivetrain concepts. Parallel hybrid drivetrains form the group of concepts in which a mechanical coupling of the internal combustion engine (ICE) with the wheels is possible and all drives can simultaneously provide torque for propulsion [4]. Five basic parallel hybrid topologies (P0-P4) are distinguished depending on the arrangement of the EM in the power path from the ICE (internal combustion engine) to the wheels (Figure 1). By combining the EM arrangements of the basic topologies, new drivetrain variants can be created, such as the exemplary P0P2 hybrid in Figure 1. Dual-clutch transmissions are particularly well suited for HEVs, as they combine high efficiency with a 
high level of driving comfort [5] and meet the additional functional requirements with few design modifications [6]. In the P2 arrangement, they find a particularly broad application in HEVs [7].
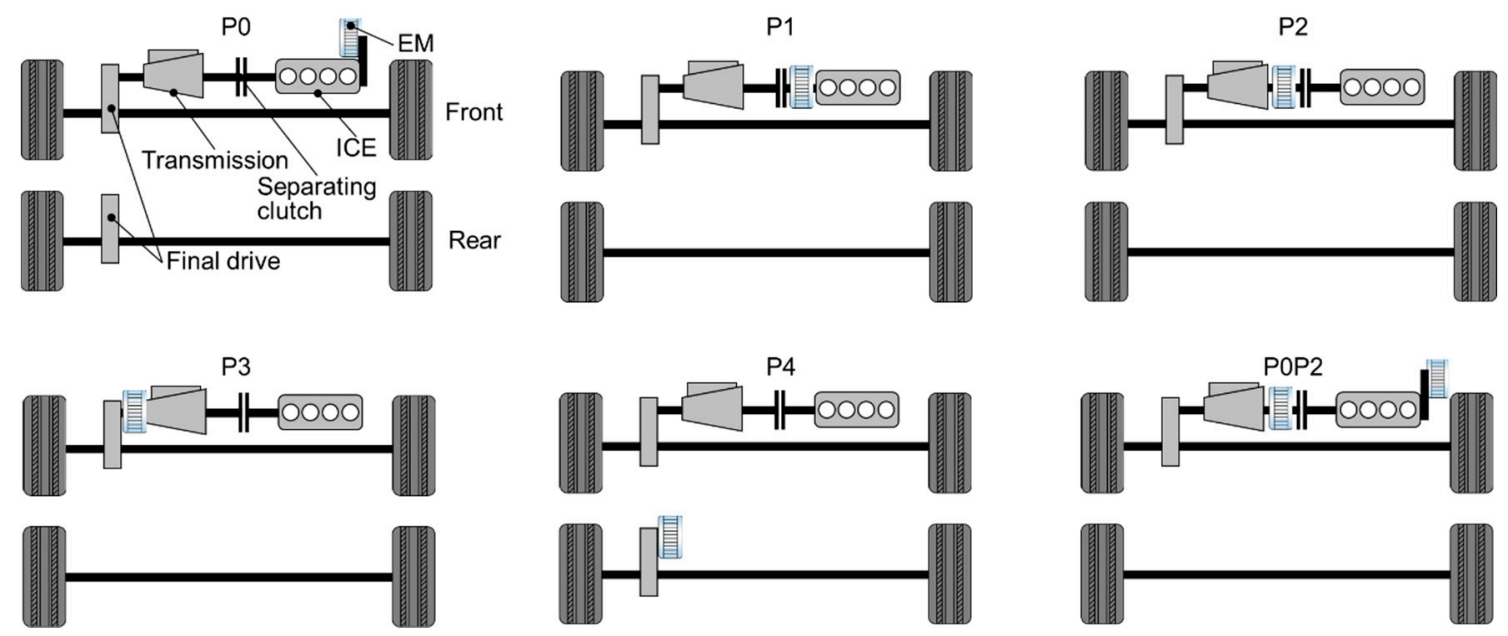

Figure 1. Arrangements of the EM (electric machine) in basic parallel hybrid topologies (P0-P4) and exemplary arrangement through combination (P0P2).

Among the development goals of the automotive industry, reliability is of central importance alongside efficiency, emissions and costs [8]. Automotive products are multidisciplinary and subject to increasing complexity with a high number of variants. The later correction of errors that occur during early development phases is particularly cost-intensive [9]. For this reason, the reliability of vehicle transmissions is continuously taken into account, from the early design phases to the realization of the physical product [10]. In early product creation phases, lifetime calculation is often used to assess reliability [11]. In the process, occurring loads for the investigated component are compared with their bearable loads and converted into component damage or lifetime. Occurring loads are, for instance, extracted from real driving tests, or are generated synthetically and condensed to load spectra by means of a suitable classification method. Xue et al. [12] present a method to extract real load data for the durability design of transmissions considering numerous influences on the loads, and apply it to a conventional vehicle, a BEV and an HEV. Approaches to generating of synthetic load data can be found in $[13,14]$. Belingardi et al. [15] investigate the influence of dynamic overloads on the lifetime of gears in the transmission of an electric vehicle. For this purpose, the dynamic factor is determined analytically, using a rigid and a fully elastic simulation model of the gear pairs. A lifetime calculation of a six-speed manual transmission in a conventional vehicle drivetrain is performed by Kamper et al. in [16]. The development of a simulation model and a method of calculating the damage in gears in a conventional drivetrain is described by Foulard et al. in [17]. An approach to determining the remaining lifetime of transmission gears in real vehicle operation is presented by Foulard et al. in [18] and applied to a manual transmission in a conventional vehicle. Major influences on damage include the clutch actuation in gearshifts, the inclusion of the lower drivetrain natural frequencies in the model and special events such as the loss of tire adhesion. Negative torques from ICE coast operation are indicated as negligible [19]. A load-related operating strategy for the vehicle is presented and discussed in detail in [20], regarding damage to gears. Haq et al. [21] use a simulation model to predict the load spectra and damage in the gears of a vehicle transmission.

The computational approaches mentioned so far are suitable for evaluating reliability in product development. In addition, experimental methods are used to ensure the reliability of the implemented physical product. For this purpose, load spectra in the form of test cycles are used in running tests. In [22], Friedmann et al. present a method of carrying out customer-representative gear testing with regard to service life in a time- and cost-optimized manner. 
Transmissions in hybrid drivetrains can be subject to additional loads compared to their use in conventional drivetrains, which must be taken into account in order to dimension the components and ensure reliable operation. In [23], Fugel et al. investigate the influence of a parallel and a power split hybrid drivetrain on the transmission input torque and compare the results to a conventional drivetrain. For this purpose, they use a simulation model and evaluate it for a given vehicle with varying drivers and driving routes. In [24], Lavall summarizes the influences of hybridization on the component loads in the transmission as a "hybrid effect." To this end, Lavall mentions additional torques in drive and coast operation during boosting and regeneration, additional functions such as electric launch, changed vehicle parameters such as weight and changed component properties such as housing geometry. It is pointed out that it is necessary to take coast operation into account in the lifetime calculation, since regeneration can increase the load in negative power flow direction. An application-oriented reduction of the transmission input torque to achieve a target gear lifetime is presented in [25].

In the presented studies, the critical role of gears on transmission lifetime is well established. Like gears, bearings are among the high-risk transmission components [26] and cause $15 \%$ of transmission failures, making them the second most frequent cause of transmission failures after gears [8]. A literature search revealed few studies on bearing lifetime in automotive transmissions and especially hybrid applications. The aim of this paper is to investigate the influence of hybridization in terms of regeneration on the lifetime of bearings as highly critical elements in a dual clutch transmission. For this purpose, we use a detailed drivetrain model of a parallel HEV. In the drivetrain topologies P0, $\mathrm{P} 1$ and $\mathrm{P} 2$, the EM is placed upstream of the transmission and has to transmit additional power in the coast direction to achieve regeneration. The power transfer leads to additional loads acting on the machine elements and to a distinct lifetime behavior.

The remaining part of the paper is structured as follows. Section 2 first introduces the use case considered for this study. Afterwards, the underlying method used for calculating the lifetime and the system simulation model are introduced and explained. Section 3 presents the results of the simulation and lifetime calculations for a conventional and a hybrid drivetrain, as well as a sensitivity analysis. Finally, Section 4 gives a brief summary, a conclusion and an outlook regarding necessary and possible future work.

\section{Materials and Methods}

The investigations of this contribution are carried out by means of a simulation of an exemplary system. For this purpose, the investigated vehicle and transmission are presented in Section 2.1. The approach to determine component lifetimes that fail due to fatigue and the application to bearing lifetimes is explained in Section 2.2. The calculation of the necessary load and motion quantities for the determination of bearing lifetimes is carried out with the help of a 1D drivetrain model. This model is presented in Section 2.3.

\subsection{Use Case}

In this paper, a front-wheel drive C-segment [27] hybrid vehicle in P2 configuration is considered as a use case. It is driven by a diesel ICE and a PMSM (permanent magnet synchronous motor) EM. The vehicle data are given in Table 1. The drivetrain structure is presented in more detail in Section 2.3.

Table 1. Vehicle data.

\begin{tabular}{cc}
\hline Parameter & Value \\
\hline Vehicle class & C-segment \\
Vehicle mass $\mathrm{m}_{\mathrm{veh}}$ & $1600 \mathrm{~kg}$ \\
ICE Power & $125 \mathrm{~kW}$ \\
EM Power & $83 \mathrm{~kW}$ \\
\hline
\end{tabular}


Power is transmitted via a six-speed dual-clutch transmission with an integrated differential. The layout of the transmission the structure of the simulation model presented in Section 2.3 is shown in Figure 2. The EM is mounted on the input side of the clutch drum. The dual clutch connects the clutch drum with one input shaft each. This ensures, with respective actuation from the transmission control unit (TCU), that the power flow is not interrupted during gear shifts. The two input shafts are arranged concentrically; input shaft 2 is designed as a hollow shaft for this purpose. The idlers of gears 1-6 and the reverse gear are mounted on needle bearings on the intermediate shafts. They are axially fixed by thrust washers. Input shaft 1 is mounted in locating bearing 6 and is supported by radial bearings 4 and 6 and thrust bearing 3 on input shaft 2 . Input shaft 2 is mounted in the housing via nonlocating bearing 7 . The intermediate shafts are supported in the housing by locating bearings 15 and 17 and nonlocating bearings 16 and 18, respectively. The differential is mounted in an adjusted bearing arrangement in an $X$ layout (bearings 1 and 2). The reversal shaft is supported by two floating bearings and thrust washers. The transmission has a total of 20 bearings.

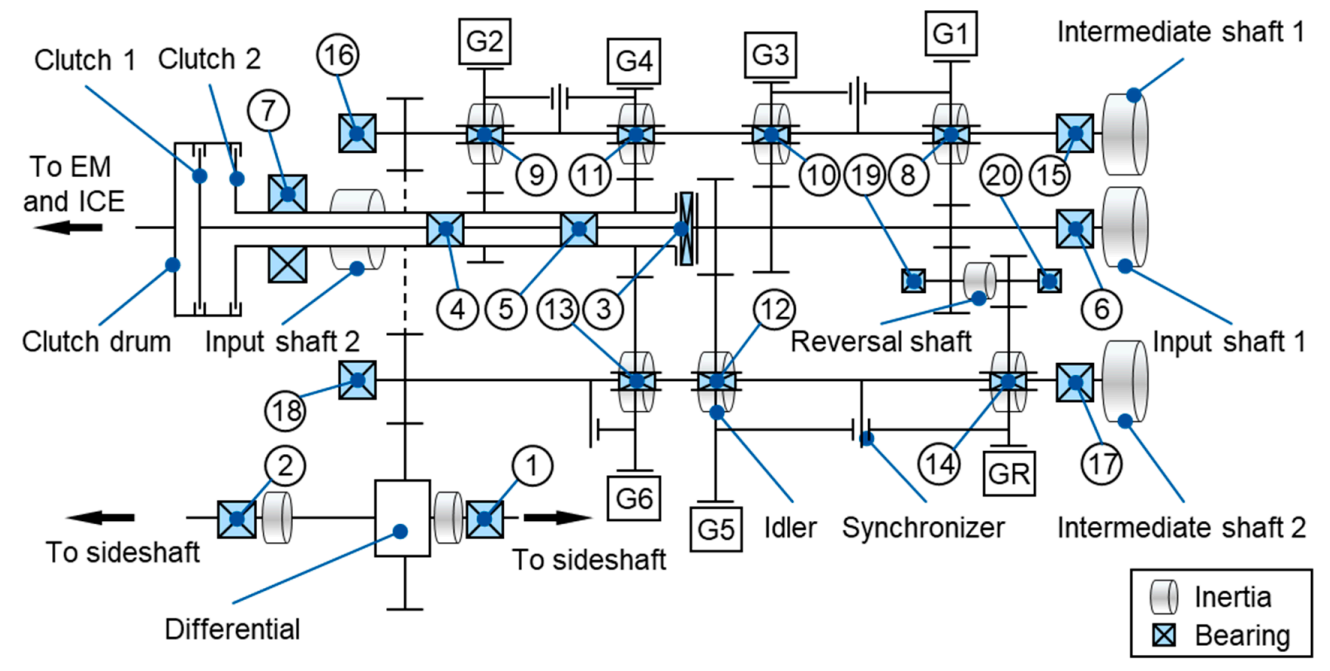

Figure 2. Transmission layout and structure of its torsional rigid-body model.

\subsection{Lifetime Calculation}

In this paper, the bearing lifetime of the transmission is calculated on the basis of damage due to material fatigue. For this, the approach according to Figure 3 is applied. As shown in [28], the approach can also be adapted to other machine elements that fail due to fatigue, such as gears or shafts. By making suitable assumptions, wear-related failures such as those of friction clutches or seals can also be calculated [29], but these are omitted in this paper for brevity. The approach for considering component lifetime is based on existing standards and established procedures in the automotive industry. The core aspect of the approach is the comparison of occurring and bearable loads, which is necessary for the quantitative assessment of component lifetime [26].

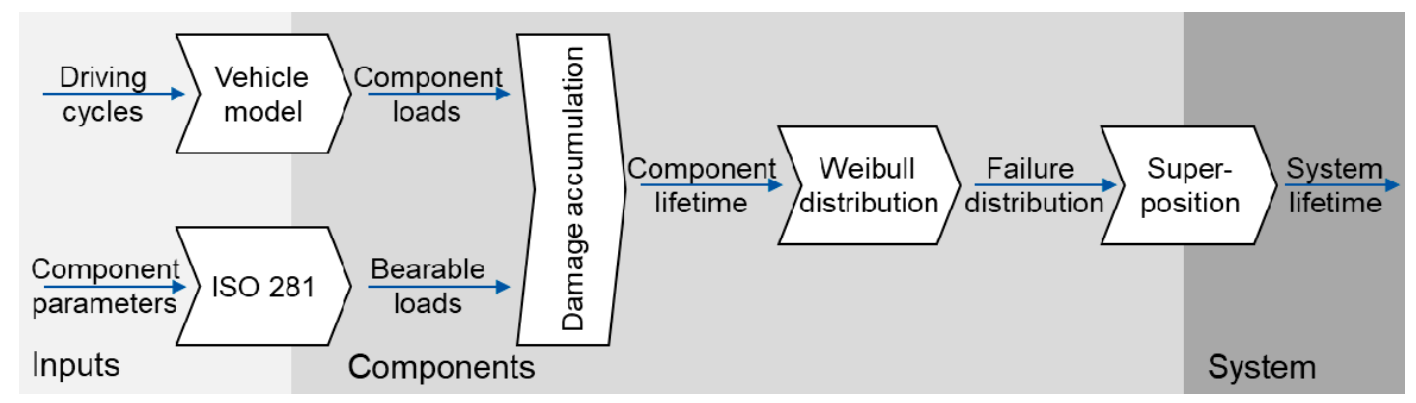

Figure 3. Approach for determining the system lifetime [28]. 
Here, a comparison is made computationally using a damage accumulation hypothesis. An alternative to simulation is testing, but this is usually associated with a high expenditure of time and money. Initially, driving cycles are defined to determine the bearing loads for the computational analysis. The cycles represent the assumed use of the transmission consisting of various boundary conditions such as driver, driving distance, special events and others. The influence of the vehicle is represented by a simulation model. The simulation model considers the interaction of the subsystems in a selected level of detail and outputs time-based records of the bearing loads (axial and radial forces) and their frequency of occurrence in the form of the rotational speed. The speed and load of the bearings depend on which gear is engaged, whether the vehicle accelerates or decelerates and whether gearshifts occur. In the case of measurement of the occurring loads, the bearing loads are typically calculated back from an easily measurable variable, such as the input torque of the transmission [26]. Bearings can be subjected to a combined load from radial $F_{R}(t)$ and axial forces $\mathrm{F}_{\mathrm{A}}(\mathrm{t})$. However, for the comparison of the occurring and bearable loads, a reduced quantity is required, i.e., the dynamically equivalent force $\mathrm{P}(\mathrm{t})$. The calculation is carried out according to Equation (1). $\mathrm{X}$ and $\mathrm{Y}$ are the dynamic radial and axial load factor, respectively. They can either be obtained directly from the bearing manufacturer or calculated using analytical equations of ISO 281 [30].

$$
P(t)=X \cdot F_{R}(t)+Y \cdot F_{A}(t)
$$

The resulting time records $\mathrm{P}(\mathrm{t})$ per bearing are then simplified to load spectra with the aid of the two-parametric time-at-level counting [31]. The occurring loads and speeds are divided into 64 classes according to the recommendation of [32].

The bearable loads of the bearings required for the accumulation of damage are determined using ISO 281 [30]. The possible number of rotations $\mathrm{L}_{\mathrm{i}}$ of a load class $\mathrm{i}$ with a failure probability of $10 \%$ is obtained in $10^{6}$ bearing revolutions, according to Equation (2).

$$
\mathrm{L}_{\mathrm{i}}=\mathrm{aISO}_{\mathrm{ISO}} \cdot\left(\frac{\mathrm{C}}{\mathrm{P}_{\mathrm{i}}}\right)^{\mathrm{p}}
$$

The life modification factor aIso takes into account the type, quality and geometry of the bearing, as well as the fatigue limit of the raceway material [30]. C is the dynamic load rating of the bearing, and can be obtained from the bearing manufacturer. The exponent $p$ is 3 for ball bearings and $\frac{10}{3}$ for roller bearings. $P_{i}$ is the dynamically equivalent bearing load of a load class. Information on the bearing data, taken from bearing manufacturer catalogues, can be found in Table A1.

In the damage accumulation, occurring and bearable loads are compared and summed to yield damage D over all $\mathrm{k}$ load classes (Equation (3)). $\mathrm{n}_{\mathrm{i}}$ denotes the number of bearing revolutions occurring for an individual load class in the cycle.

$$
\mathrm{D}=\sum_{\mathrm{i}=1}^{\mathrm{k}} \frac{\mathrm{n}_{\mathrm{i}}}{\mathrm{L}_{\mathrm{i}}}
$$

Based on the cumulative damage $\mathrm{D}$ and the cycle duration $\mathrm{T}_{\text {cycle, }}$ the component lifetime $\mathrm{B}_{10}$ of a bearing is calculated (Equation (4)).

$$
\mathrm{B}_{10}=\frac{\mathrm{D}}{\mathrm{T}_{\text {cycle }}}
$$

The failure distribution of a single bearing $F_{j}(t)$ over time is described using the Weibull distribution (Equation (5)). $t_{0}$ is the failure-free time and can take values between $0.1 \cdot B_{10}$ and $0.3 \cdot B_{10}$ for bearings [32]. In this paper $t_{0}=0.2 \cdot B_{10}$ is used. $b$ is a shape parameter and equals 1.1 for ball bearings and 1.35 for roller bearings [32]. The characteristic lifetime $T_{j}$ of a single $j$ is calculated using Equation (6).

$$
F_{j}(t)=1-e^{-\left(\frac{t-t_{0}}{T_{j}-t_{0}}\right)^{b}}
$$




$$
\mathrm{T}_{\mathrm{j}}=\frac{\mathrm{B}_{10}-\mathrm{t}_{0}}{\sqrt[b]{-\log (0.9)}}+\mathrm{t}_{0}
$$

The system failure distribution or the failure distribution of all bearings as a group $\mathrm{F}_{\mathrm{B}}(\mathrm{t})$ over time is calculated by a superposition of the failure probabilities of the individual bearings. Here, it is assumed that the group of bearings fails as soon as one bearing fails. The underlying Boolean relationship is given in Equation (7).

$$
\mathrm{F}_{\mathrm{B}}(\mathrm{t})=1-\prod_{\mathrm{j}}\left(1-\mathrm{F}_{\mathrm{j}}(\mathrm{t})\right)
$$

The system lifetime or the lifetime of all bearings as a group with a failure probability of $10 \%$ is the time $t$ at which $F_{B}$ reaches the value 0.1.

For further information on the approach described, we refer the reader to references [28,29].

\subsection{System Model}

To determine the operating conditions of the bearings in terms of force and rotational speed, a detailed forward oriented overall vehicle model is built in Matlab/Simulink using the Simscape library. The high-level structure of the model is shown in Figure 4. The submodels are divided into ICE, EM, mechanical drivetrain, vehicle, driver and hybrid control unit (HCU). On the input side, the model receives a driving cycle-dependent time-based desired velocity $\mathrm{v}_{\text {des }}$. In the driver model, the desired velocity is compared to the actual velocity vact and the deviation is converted into an accelerator $\mathrm{x}_{\mathrm{thr}}$ or brake pedal position $\mathrm{x}_{\mathrm{brk}}$ by a PI-controller.

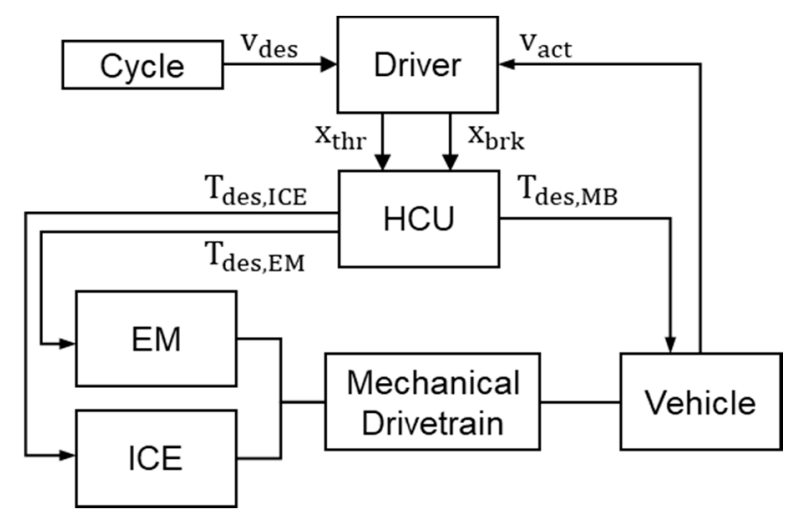

Figure 4. Modular structure of the system simulation model and exchanged quantities.

The pedal positions are converted into desired torques of the ICE $\mathrm{T}_{\mathrm{des}, \mathrm{ICE}}$, the $E M \mathrm{~T}_{\mathrm{des}, \mathrm{EM}}$ and the mechanical brake (MB) $\mathrm{T}_{\mathrm{des}, \mathrm{MB}}$ by the HCU. In this paper, a simplified operating strategy is considered, since the influence of regenerative braking on the bearing lifetime of the transmission is investigated. The vehicle is driven purely by the ICE. The deceleration of the vehicle is implemented by splitting the braking torque between ICE, EM and the MB. For this, a required deceleration torque $T_{\text {dem,brk }}$ is calculated from the brake pedal position. This deceleration torque is applied with priority by the drag torque of the ICE. The desired ICE torque is calculated according to Equation (8) with the current transmission gear ratio $\mathrm{i}_{\mathrm{G}}$ (see Table $\mathrm{A} 2$ ).

$$
\mathrm{T}_{\mathrm{des}, \mathrm{ICE}}=\frac{\mathrm{T}_{\mathrm{dem}, \mathrm{brk}}}{\mathrm{i}_{\mathrm{G}}}
$$


If the maximum drag torque $\mathrm{T}_{\max }$ ICE of the ICE is not sufficient for the deceleration of the vehicle, the EM is used as a generator (Equation (9)).

$$
\mathrm{T}_{\text {des, } \mathrm{EM}}=\frac{\mathrm{T}_{\text {dem,brk }}}{\mathrm{i}_{\mathrm{G}}}-\mathrm{T}_{\max , \mathrm{ICE}}
$$

For stronger braking which cannot be achieved by the drag torque of the ICE and the generator operation of the EM T $\mathrm{max}_{\mathrm{maM}, \mathrm{ICE}}$, the mechanical brake is applied (Equation (10)).

$$
\mathrm{T}_{\mathrm{des}, \mathrm{MB}}=\mathrm{T}_{\mathrm{dem}, \mathrm{brk}}-\mathrm{T}_{\mathrm{max}, \mathrm{EM}, \mathrm{ICE}}
$$

In the ICE model, the desired torque $\mathrm{T}_{\text {des,ICE }}$ is converted into an acting torque $\mathrm{T}_{\mathrm{act}, \mathrm{ICE}}$ by a first-order delay with a time constant of $t_{\mathrm{ICE}}=0.203 \mathrm{~s}$ [33]. The maximum drive torque is limited in the model by a full load characteristic curve. For coast operation, an analytically derived thrust characteristic curve is used [26], which decreases in proportion to engine speed to $-10 \%$ of the nominal torque (Figure 5a).

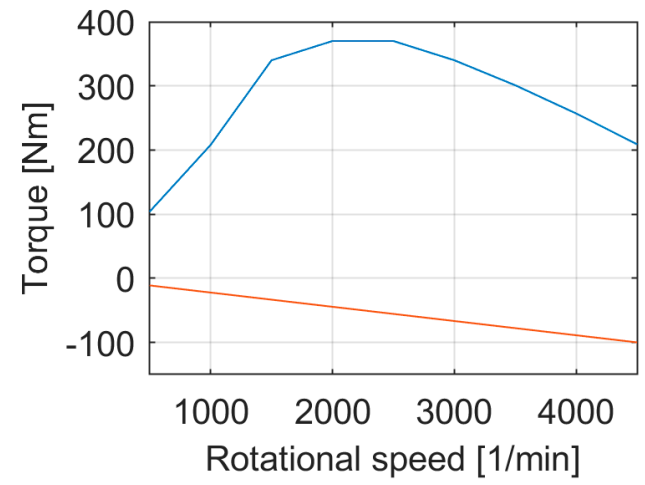

(a)

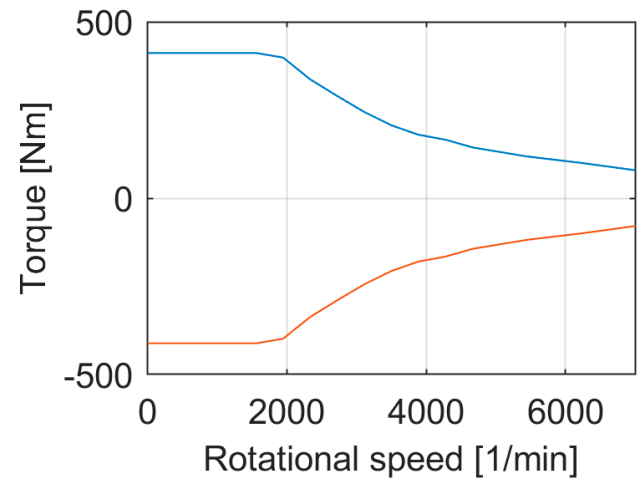

(b)

Figure 5. (a) Full-load characteristic curve (blue) and thrust characteristic curve (red) of the ICE model; (b) traction (blue) and generator (red) torque limits of the EM model.

In the $\mathrm{EM}$ model, the desired torque $\mathrm{T}_{\mathrm{des}, \mathrm{EM}}$ is converted into an acting torque $\mathrm{T}_{\mathrm{act}, \mathrm{EM}}$ by a first-order delay with a time constant of $\mathrm{t}_{\mathrm{EM}}=0.04 \mathrm{~s}$ [33]. The maximum deliverable motor and generator torques are limited by power hyperbolas and constant torque curves (Figure $5 b$ ).

In the vehicle model, the effective driving resistance force $F_{\text {drag }}$ is calculated as a function of the vehicle velocity $\dot{x}_{v e h}$ according to Equation (11). $\mathrm{f}_{\mathrm{d} 0}$ and $\mathrm{f}_{\mathrm{d} 1}$ are driving resistance coefficients which cause constant and velocity proportional driving resistances. $\mathrm{f}_{\mathrm{d} 2}$ causes a resistance force which is proportional to the square of the vehicle velocity. The values of the coefficients are listed in Table A3.

$$
\mathrm{F}_{\mathrm{drag}}=\mathrm{f}_{\mathrm{d} 0}+\mathrm{f}_{\mathrm{d} 1} \cdot \dot{\mathrm{x}}_{\mathrm{veh}}+\mathrm{f}_{\mathrm{d} 2} \cdot \dot{\mathrm{x}}_{\mathrm{veh}}^{2}
$$

The forces and torques described above act on a torsional vibration model of the mechanical drivetrain (Figure 6). Individual inertias are represented as cylinders connected by spring-damper combinations or clutches. External torques act through the ICE, EM, MB and driving resistance. For the recommended [19] consideration of the lower natural frequencies of the drivetrain, the dual mass flywheel (DMF), the side shafts and the tires were modeled elastically [34]. The wheel-to-ground contact is modelled ideally (i.e., ideal rolling), since special events such as loss of tire grip will not be investigated in this paper. 


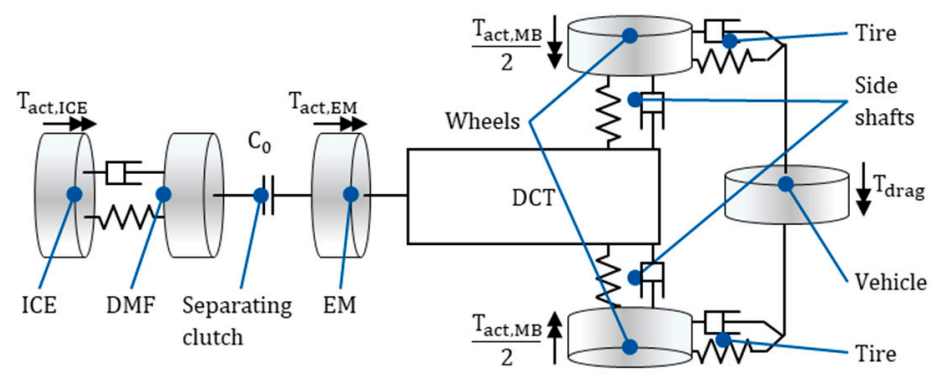

Figure 6. Structure of the torsional vibration model used for the hybrid drivetrain. For the conventional drivetrain the torque $\mathrm{T}_{\mathrm{act}, \mathrm{EM}}$ is omitted and the inertia at the transmission input is added to the inertia of the clutch drum.

Since the vehicle motion is calculated in the torsional vibration model and the driving resistances are calculated in the translational degree of freedom, a transfer of the corresponding quantities is carried out with Equations (12) and (13). $\mathrm{T}_{\mathrm{drag}}$ is the equivalent driving resistance torque for a driving resistance force acting on the tire radius $\mathrm{r}_{\text {tire. }}$. The vehicle velocity is calculated from the angular velocity of the equivalent inertia of the vehicle $\dot{\phi}_{\mathrm{veh}}$ in the torsional vibration model.

$$
\begin{gathered}
\mathrm{T}_{\text {drag }}=\mathrm{F}_{\mathrm{drag}} \cdot \mathrm{r} \\
\dot{\mathrm{x}}_{\mathrm{veh}}=\dot{\phi}_{\mathrm{veh}} \cdot \mathrm{r}_{\text {tire }}
\end{gathered}
$$

The motion of the individual drivetrain inertias is described in the torsional degree of freedom and is shown as an example for the vehicle inertia in Equation (14).

$$
\mathrm{J}_{\mathrm{veh}} \cdot \ddot{\phi}_{\mathrm{veh}}=\mathrm{c}_{\text {tire }}\left(\phi_{\text {wheel }, 1}+\phi_{\text {wheel, } \mathrm{r}}-2 \phi_{\text {veh }}\right)+\mathrm{d}_{\text {tire }}\left(\dot{\phi}_{\text {wheel }, 1}+\dot{\phi}_{\text {wheel, } \mathrm{r}}-2 \dot{\phi}_{\mathrm{veh}}\right)-\mathrm{T}_{\mathrm{drag}}
$$

$\ddot{\phi}, \dot{\phi}$ and $\phi$ thus describe angular acceleration, angular velocity and angle of the corresponding inertia, respectively. $c_{\text {tire }}$ and $d_{\text {tire }}$ are stiffness and damping of the tires, respectively. The equivalent inertia of the vehicle $J_{v e h}$ is calculated using Equation (15). The parameters of the torsional vibration model are summarized in Table A4.

$$
\mathrm{J}_{\mathrm{veh}}=\frac{1}{2} \cdot \mathrm{m}_{\mathrm{veh}} \cdot \mathrm{r}_{\text {tire }}^{2}
$$

A rigid body model of the transmission (Figure 2), including a transmission control unit (TCU), is embedded in the drivetrain model. The overall purpose of the transmission model is to calculate the motion and load condition of each bearing. The rotational speeds of the bearings directly result from the torsional motion of the model, which is calculated for each individual shaft using Equation (16). $\mathrm{J}_{\text {shaft }}$ is an individual shaft inertia in and $\ddot{\phi}_{\text {shaft }}$ its corresponding angular acceleration. $T_{i}$ are the torques acting on the shaft and consider driving torques and torque losses [35].

$$
\mathrm{J}_{\text {shaft }} \cdot \ddot{\phi}_{\text {shaft }}=\sum_{\mathrm{i}} \mathrm{T}_{\mathrm{i}}
$$

The bearing loads result from the support of the tangential $\left(\mathrm{F}_{t}\right)$, radial $\left(\mathrm{F}_{\mathrm{r}}\right)$ and axial $\left(\mathrm{F}_{\mathrm{a}}\right)$ gear forces. To determine the bearing forces, static equilibria are evaluated for the individual transmission shafts (Equations (17) and (18)) at each time step. However, in Equation (18) only the bending moments are considered, since the torsional behavior is calculated in the rigid body model.

$$
\begin{aligned}
& \sum_{\mathrm{i}} \mathrm{F}_{\mathrm{i}}=0 \\
& \sum_{\mathrm{i}} \mathrm{M}_{\mathrm{i}}=0
\end{aligned}
$$


The forces are strongly dependent on the geometry of the shaft and gears, as well as the arrangement of the gears on the shaft. Figure 7 shows an exemplary force diagram of intermediate shaft 1 for the calculation of bearing forces $\mathrm{F}_{\mathrm{b} 15}$ and $\mathrm{F}_{\mathrm{b} 16}$. For illustration purposes, all forces are rotated into the section plane, since the tooth meshes are not arranged identically around the circumference for all gears. The locations (gear diameters $\mathrm{d}_{\mathrm{G}}$ and shaft section lengths 1 ) of the gear forces are considered in the model. FD is a gear of the final drive.

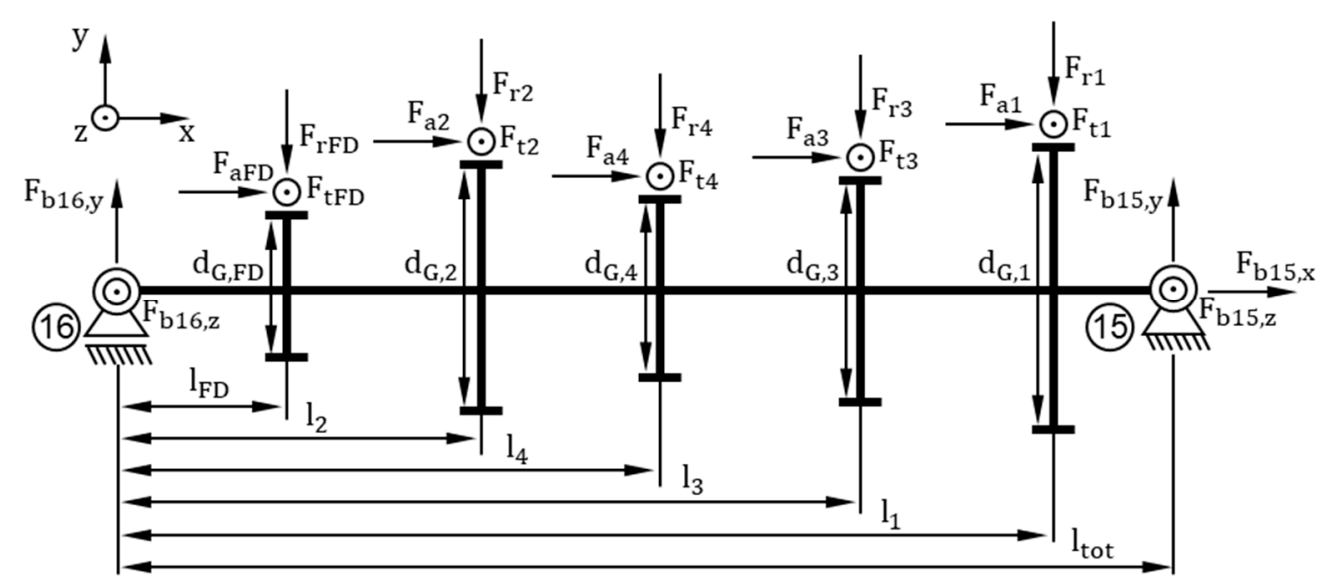

Figure 7. Force diagram of the first intermediate shaft. All forces are rotated into the section plane.

An acting tangential force $F_{t}$ is calculated using Equation (19). $T_{G}$ is the acting torque on a gear wheel. It is read from the transmission model at each time step, taking into account the meshing losses. The direction of the tangential force depends on the torque direction.

$$
\mathrm{F}_{\mathrm{t}}=\frac{2 \cdot \mathrm{T}_{\mathrm{G}}}{\mathrm{d}_{\mathrm{G}}}
$$

The acting radial force $F_{r}$ is calculated using Equation (20). $\alpha_{n}$ is the normal pressure angle and $\beta$ the helix angle of the corresponding gear. The amplitude of the radial force is dependent on the amplitude of the tangential force. Since the radial force is always oriented to the center of the gear, the radial force of an idler corresponds to its needle bearing load.

$$
\mathrm{F}_{\mathrm{r}}=\left|\mathrm{F}_{\mathrm{t}}\right| \cdot \frac{\tan \left(\alpha_{\mathrm{n}}\right)}{\cos (\beta)}
$$

The axial force $\mathrm{F}_{\mathrm{a}}$ is given by Equation (21). Its direction depends on the direction of the tangential force, as well as on the helix direction of the gear.

$$
\mathrm{F}_{\mathrm{a}}=\mathrm{F}_{\mathrm{t}} \cdot \tan (\beta)
$$

In addition to the calculation of the motion and load of the individual bearings, the influences of gear shifts, synchronizations and losses are taken into account. In gear shifts and synchronizations of gears, additional synchronization torques act in addition to the driving resistances, which cause higher gear forces and must ultimately be supported by the bearings. For this purpose, both input clutches and the seven synchronizers were modeled, which are operated by an implemented TCU on the basis of a shift map. This enables launching with the ICE and gear shifts without interrupting the tractive force. These friction elements have identical models that distinguish between a slip and a stick state. In the slip state, the torque capacity set by the TCU acts on the two neighboring inertias of the friction element as a synchronizing torque. If both speeds are synchronized, the friction element changes to the stick state and the torque transmitted by the friction element is limited by the set torque capacity. For reasons of simplification, the set torque of the TCU is applied without delay to the 
friction elements. To evaluate transmission losses, modules are implemented which take into account load-dependent and -independent bearing and gear losses, drag losses of the wet input clutches and seal losses. The loss calculation was validated in an earlier publication in large parts of the operating range of the transmission so that the calculated power flows were plausibly represented. For further information on the validation, transmission controls and loss calculation, we refer the reader to [35].

\section{Results}

In this section, the results of the evaluation of the simulation model and the subsequent lifetime calculation are presented. First, in Section 3.1, the load and the resulting bearing lifetime of the conventional drivetrain are evaluated. The results of the hybrid drivetrain are compared to the conventional drivetrain in Section 3.2. In Section 3.3, a sensitivity analysis is performed to determine the influence of the maximum regeneration torque on the bearing lifetime.

For all investigations, the Worldwide Harmonized Light Vehicles Test Cycle (WLTC) [36] was chosen as the representative cycle. Details of its properties are summarized in Table A5. The WLTC was chosen because it has combined cycle components of low, medium, high and extra high vehicle velocities. In addition, vehicle launches, gear shifts and decelerations occur. Special conditions such as loss of tire adhesion or misuse do not occur in the WLTC, and are not considered in this paper. With the choice of the WLTC, the driver's influence on the calculated loads is also deliberately omitted. In general, representative load cycles are subject to extensive boundary conditions. Load spectra are experimentally measured or generated manufacturer-specifically, taking into account the driver, environment and vehicle [14].

\subsection{Conventional Drivetrain}

The load spectrum at the transmission input resulting from the applied driving cycle is shown in Figure 8 . Here, the transmission input torque is shown versus the transmission input speed. The color indicates the frequency of occurrence of the respective operating point. The torque at the transmission input is to be considered here as a representation of the bearing load, since the gear forces to be supported by the bearings are proportional to the torque. The range of positive torques arises during drive operation. Negative torques occur during coast operation of the ICE. Negative torques beyond the thrust characteristic curve of the ICE occur during downshifts in coasting. In this case, an overtorque is applied by the clutches to synchronize the ICE to the transmission input speed.

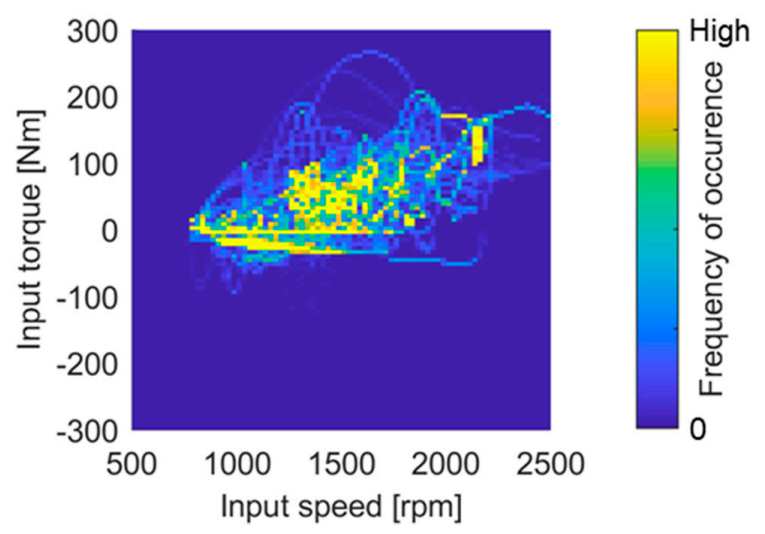

Figure 8. Load spectrum of the transmission input torque for the conventional drivetrain in the WLTC.

The failure probabilities of the individual rolling bearings of the transmission and their superposition over the travel distance are shown in double-logarithmic form in Figure 9. In [37], the transmission $B_{10}$-lifetime is given as $150,000-250,000 \mathrm{~km}$, depending on the vehicle type. In $[12,38]$, the lifetime of $300,000 \mathrm{~km}$ for the vehicle and transmission is given respectively without specifying the probability of failure. Therefore, the superposed lifetime of the bearings with about 195,000 $\mathrm{km}$ in the 
WLTC is considered plausible by the authors. The failure distribution is dominated by bearings 16 and 18. They are used as locating bearings for the two intermediate shafts, and are particularly frequently present in the power flow. In addition, as locating bearings, they are subjected to the combined load of axial and radial bearing forces resulting from the gears. The high scattering of bearing lifetimes of two orders of magnitude according to the authors' assessment can be attributed to the fact that different load assumptions than those caused in the WLTC and the vehicle under consideration were used for the design of the transmission.

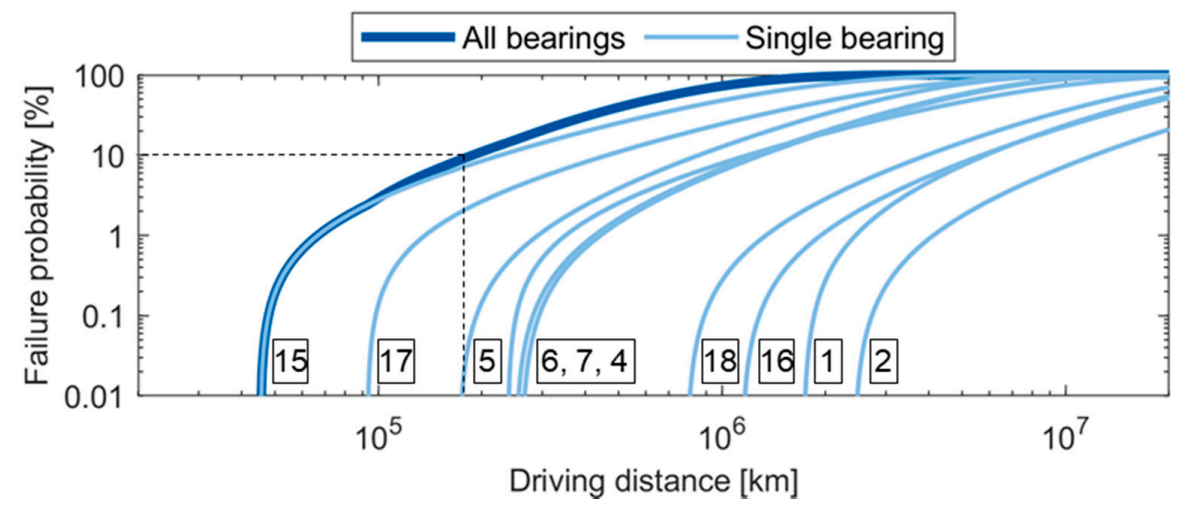

Figure 9. Failure probabilities of the individual bearings and the bearings as a group for the conventional drivetrain. The position numbers of the bearings are shown framed (see Figure 2). The dotted line indicates the $\mathrm{B}_{10}$-lifetime with 195,000 km.

According to the calculation approach presented, the needle roller bearings used are fatigue-resistant, since they only experience significant operating loads in the synchronized case, i.e., without relative motion of the bearing raceways. Loads that occur during synchronization and due to bearing friction do not contribute to damage in this case. In fact, wear in the form of indentations in the raceway under high stationary loads is mentioned in the literature as a frequent cause of failure $[38,39]$. If a lifetime model becomes available, the influence of the needle bearings can be included in the approach.

\subsection{Hybrid Drivetrain}

The calculated load spectrum of the transmission input torque for the HEV is shown in Figure 10. The positive torque range remains essentially unchanged, since propulsion is still performed by the ICE. However, operating points with a high negative torque occur more frequently due to regeneration.

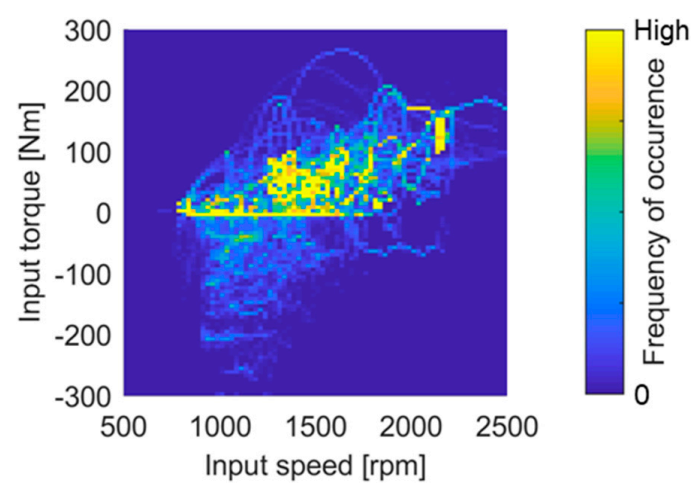

Figure 10. Load spectrum of the transmission input torque for the hybrid drivetrain without limitation of the regeneration torque in the WLTC. Scaling of the color bar identical to Figure 8. 
The resulting failure probabilities of the bearings for the HEV are shown in Figure 11. The load spectrum of the hybrid drivetrain causes a shift in the bearing lifetimes towards lower driving distances. In total, the superposed lifetime of all bearings is $123,000 \mathrm{~km}$, which corresponds to a reduction of $36.9 \%$ compared to the conventional drivetrain. In addition to the lower overall lifetime, the curves scatter more strongly compared to the conventional drivetrain.

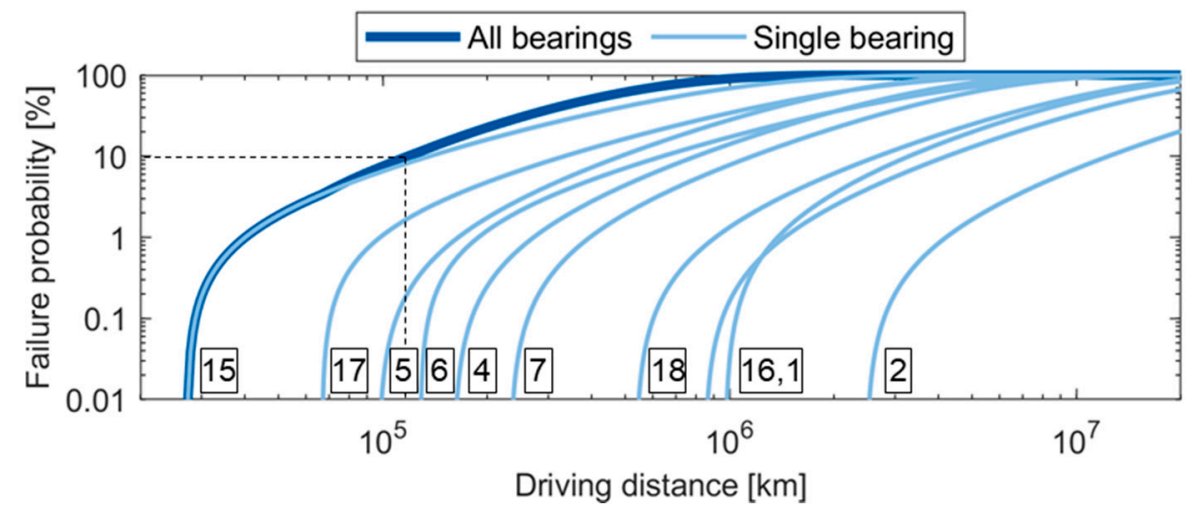

Figure 11. Failure probabilities of the individual bearings and the bearings as a group for the hybrid drivetrain. The position numbers of the bearings are shown framed (see Figure 2). The dotted line indicates the $\mathrm{B}_{10}$-lifetime of the bearing group with $123,000 \mathrm{~km}$.

\subsection{Sensitivity Analysis}

In this section, a parameter variation of the maximum regeneration torque is performed. In reality, the limitation of the regeneration torque may have its cause on the electrical, mechanical and human side, and is not unusual in practice. Boundary conditions such as efficiency, component limits and driving comfort influence the control of the regeneration process [40]. The load cycles presented in [12] show a clear limitation of the regeneration torque. This may be due to a limitation of the charging power when the battery is close to fully charged [41]. On the mechanical side, an overload of the transmission can always be avoided by limiting the recuperation torque by controls. As an alternative, a load-related operating strategy for the vehicle can be implemented, which adjusts the possible maximum torque on the basis of the so far experienced component damage.

Figure 12 shows an exemplary load spectrum of the transmission input torque for the hybrid drivetrain with a regenerative torque limit of $100 \mathrm{Nm}$ in the WLTC. The limitation can be seen by an increase of the operating points at $-100 \mathrm{Nm}$, whereby operating points smaller than $-100 \mathrm{Nm}$ are caused by the overtorques of the clutches in powershifting.

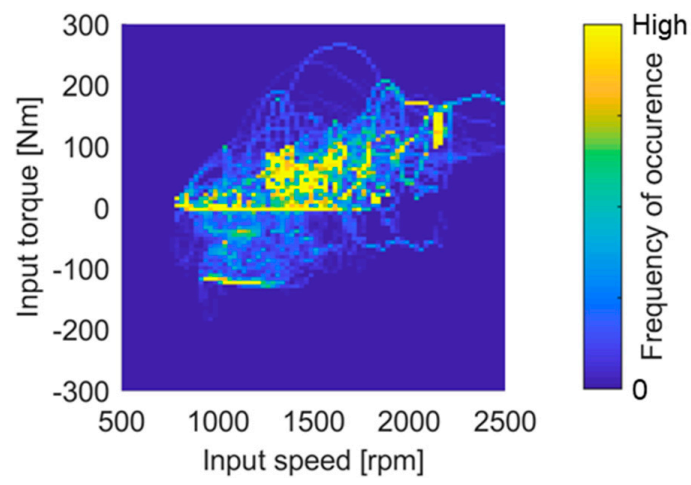

Figure 12. Load spectrum of the transmission input torque for the hybrid drivetrain with a regenerative torque limit of the electric machine of $-100 \mathrm{Nm}$ in the WLTC. Scaling of the color bar identical to Figure 8. 
Figure 13 depicts the results of the parameter variation of the maximum regenerative torque of the EM. It can be seen that with increasing maximum regenerative torque, the life of the bearings decreases. The increasing gradient of the bearing life with increasing recuperation torque can be explained by the decreasing number of operating points of high regenerative torques.

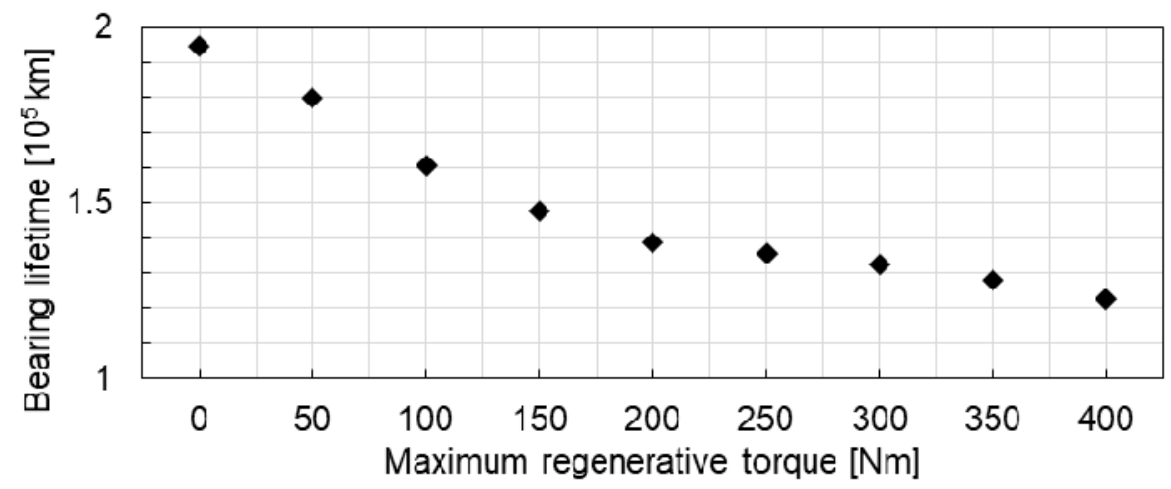

Figure 13. Results of the sensitivity analysis. Bearing lifetime over maximum regenerative torque in the WLTC.

\section{Summary, Conclusions and Outlook}

In this paper, the bearing lifetime of a transmission in a passenger car application was investigated and the influence of regenerative braking on this lifetime was quantified. Here, both a conventional and a parallel hybrid drivetrain were investigated. The bearing lifetimes were calculated using ISO 281 as part of a method for estimating the lifetime of technical systems. The loads on the rolling bearings in the transmission were determined with the help of a detailed drivetrain model consisting of ICE, EM, mechanical drivetrain, vehicle, driver and HCU. In the conventional drivetrain, the EM model was omitted. To take into account the additional loads from the eigenbehavior of the drivetrain, the DMF, side shafts and tires were considered to be elastic. The WLTC was chosen as the representative driving cycle. Additional loads from the actuation of the clutches in gear shifts were taken into account by the implemented power shifts. A simple approach was considered as the operating strategy, which splits the driver's braking torque demand between the drag torque of the ICE, the EM and the MB.

The results show that in the conventional drivetrain, the bearing lifetime of the locating bearings of the intermediate shafts dominates the failure distribution. The lifetime of the bearings as a group was evaluated as plausible on the basis of literature references. In the hybrid drivetrain without torque limitation, a $36.9 \%$ reduction in bearing lifetime was determined. The lifetime in the hybrid drivetrain is shorter, because high negative input torques occur more frequently during regenerative braking. These torques cause additional bearing loads, depending on the gear engaged. A reduction of the regenerative torque, as can be justified by the numerous boundaries of regenerative braking, was investigated in a sensitivity analysis. The bearing lifetime decreases with falling gradient up to the maximum regenerative torque of the EM.

The findings reported here demonstrate that the additional loads occurring in HEV must be taken into account in transmission development and operation. Design possibilities are a stronger dimensioning of the components, a design adaptation of the transmission layout or the use of a hybrid topology with a different position of the EM. If the regeneration can be realized without additional power flow through the transmission (e.g., topologies P3 or P4), this influence on the lifetime remains negligible. However, these topologies require a higher speed spread of the EM.

In addition, the loads can be taken into account on the operating strategy side. During development, the operating strategy can be adapted to the load capacity of the transmission by limiting the maximum regenerative torque or by a load-related gear shifting strategy that takes into account uniform loads on the bearings. During operation, the regenerative torque can be adjusted online to the damage observed in the components. The simultaneous consideration of operating strategy and transmission lifetime 
leads to a multiobjective optimization problem, the solution of which can yield a suitable tradeoff between energy saving and transmission lifetime.

Although the results are considered plausible, and a transmission model validated with regard to losses was used, the calculation approaches should nevertheless be validated in future work. This includes the physical behavior of the torsional vibration model, as well as the bearing force calculation. The torsional vibration model can be validated by means of a modal analysis. A validation of the bearing force calculation is possible by measuring the bearing forces. However, the necessary application of strain gauges in the proximity of the bearing is costly. In addition to the physics, the results of the lifetime calculation should be validated. For this purpose, condensed durability tests mentioned in the introduction can be carried out on a test bench, or the manufacturer's return data can be evaluated. Furthermore, the control influences of the modeled TCU and HCU (e.g., calibration) should be validated. Specific use cases should be investigated through more detailed and usage-specific, experimental cycles, taking special events into account. In the future, both the method and the model can be used for more detailed investigations. For example, the influences of a variation in operating strategy, transmission layout or components can be systematically quantified.

Author Contributions: Conceptualization, C.H., S.N. and K.W.; methodology, C.H., G.J., S.N. and K.W.; formal analysis, C.H.; writing - original draft preparation, C.H. and K.W.; writing - review and editing, G.J. and S.N.; supervision, G.J. and S.N. All authors have read and agreed to the published version of the manuscript.

Funding: This research was funded by the European Regional Development Fund (ERDF) as part of the research project DUETT (Diesel hybrid vehicles for environmentally conscious mobility: networked system development in a physical and virtual environment). Reference number ERDF-0800852.

Conflicts of Interest: The authors declare no conflict of interest.

\section{Abbreviations}

$\begin{array}{ll}\text { BEV } & \text { Battery Electric Vehicle } \\ \text { DMF } & \text { Dual Mass Flywheel } \\ \text { EM } & \text { Electric Motor } \\ \text { FD } & \text { Final Drive } \\ \text { HCU } & \text { Hybrid Control Unit } \\ \text { HEV } & \text { Hybrid Electric Vehicle } \\ \text { ICE } & \text { Internal Combustion Engine } \\ \text { ISO } & \text { International Organization for Standardization } \\ \text { MB } & \text { Mechanical Brake } \\ \text { PMSM } & \text { Permanent Magnet Synchronous Motor } \\ \text { TCU } & \text { Transmission Control Unit } \\ \text { WLTC } & \text { Worldwide Harmonized Light Vehicles Test Cycle }\end{array}$

\section{Nomenclature}

$\begin{array}{lll}\alpha_{\mathrm{n}} & \text { Normal pressure angle } & \left({ }^{\circ}\right) \\ \beta & \text { Helix angle } & \left({ }^{\circ}\right) \\ \phi & \text { Angle } & (1) \\ \dot{\phi} & \text { Angular velocity } & \left(\mathrm{s}^{-1}\right) \\ \ddot{\phi} & \text { Angular acceleration } & \left(\mathrm{s}^{-2}\right) \\ \phi_{\text {veh }} & \text { Vehicle equivalent inertia angle } & (1) \\ \dot{\phi}_{\text {veh }} & \text { Vehicle equivalent inertia angular velocity } & \left(\mathrm{s}^{-1}\right) \\ \ddot{\phi}_{\text {veh }} & \text { Vehicle equivalent inertia angular acceleration } & \left(\mathrm{s}^{-2}\right) \\ \phi_{\text {wheel, }} & \text { Left wheel angle } & (1) \\ \dot{\phi}_{\text {wheel,l }} & \text { Left wheel angular velocity } & \left(\mathrm{s}^{-1}\right) \\ \phi_{\text {wheel, }} & \text { Right wheel angle } & (1)\end{array}$




\begin{tabular}{|c|c|c|}
\hline$\phi_{\text {wheel,r }}$ & Right wheel angular velocity & $\left(\mathrm{s}^{-1}\right)$ \\
\hline $\mathrm{a}_{\mathrm{ISO}}$ & Life modification factor & (1) \\
\hline $\mathrm{b}$ & Shape parameter & (1) \\
\hline $\mathrm{B}_{10}$ & Bearing lifetime with a failure probability of $10 \%$ & (h) \\
\hline c & Stiffness & $\left(\mathrm{Nm} \cdot \mathrm{rad}^{-1}\right)$ \\
\hline C & Dynamic load rating & $(\mathrm{N})$ \\
\hline $\mathrm{d}$ & Damping & $\left(\mathrm{N} \cdot \mathrm{m} \cdot \mathrm{s} \cdot \mathrm{rad}^{-1}\right)$ \\
\hline $\mathrm{d}_{\mathrm{G}}$ & Gear diameter & $(\mathrm{mm})$ \\
\hline$d_{m}$ & Mean bearing diameter & $(\mathrm{mm})$ \\
\hline $\mathrm{D}$ & Damage & (1) \\
\hline $\mathrm{f}_{\mathrm{d} 0}$ & Driving resistance parameter & $(\mathrm{N})$ \\
\hline$f_{d 1}$ & Driving resistance parameter & $\left(\mathrm{N} \cdot \mathrm{s} \cdot \mathrm{m}^{-1}\right)$ \\
\hline$f_{d 2}$ & Driving resistance parameter & $\left(\mathrm{N} \cdot \mathrm{s}^{2} \cdot \mathrm{m}^{-2}\right)$ \\
\hline $\mathrm{F}_{\mathrm{a}}$ & Axial gear force & $(\mathrm{N})$ \\
\hline $\mathrm{F}_{\mathrm{b}}$ & Bearing force & $(\mathrm{N})$ \\
\hline $\mathrm{F}_{\mathrm{A}}(\mathrm{t})$ & Axial force & $(\mathrm{N})$ \\
\hline $\mathrm{F}_{\mathrm{B}}(\mathrm{t})$ & Failure probability of all bearings over time & (1) \\
\hline $\mathrm{F}_{\text {drag }}$ & Driving resistance force & $(\mathrm{N})$ \\
\hline $\mathrm{F}_{\mathrm{i}}$ & Force i & $(\mathrm{N})$ \\
\hline$F_{j}(t)$ & Failure probability of a single bearing $j$ over time & (1) \\
\hline $\mathrm{F}_{\mathrm{r}}$ & Radial gear force & $(\mathrm{N})$ \\
\hline$F_{t}$ & Tangential gear force & $(\mathrm{N})$ \\
\hline$F_{R}(t)$ & Radial force & $(\mathrm{N})$ \\
\hline i & Index & (1) \\
\hline$i_{G}$ & Gear ratio & (1) \\
\hline j & Index & (1) \\
\hline $\mathrm{J}$ & Inertia & $\left(\mathrm{kg} \cdot \mathrm{m}^{2}\right)$ \\
\hline $\mathrm{k}$ & Number of load classes & (1) \\
\hline 1 & Length of a shaft section & $(\mathrm{mm})$ \\
\hline $\mathrm{L}_{\mathrm{i}}$ & Bearable number of rotations of a load class i & $\left(10^{6}\right)$ \\
\hline $\mathrm{m}$ & Vehicle mass & $(\mathrm{kg})$ \\
\hline $\mathrm{M}_{\mathrm{i}}$ & Moment i & $(\mathrm{N} \cdot \mathrm{m})$ \\
\hline $\mathrm{n}_{\mathrm{i}}$ & Number of bearing revolutions in a load class $i$ & (1) \\
\hline $\mathrm{p}$ & Lifetime exponent & (1) \\
\hline $\mathrm{P}(\mathrm{t})$ & Dynamically equivalent bearing load & $(\mathrm{N})$ \\
\hline$P_{i}$ & Dynamically equivalent bearing load of a load class $\mathrm{i}$ & $(\mathrm{N})$ \\
\hline$r_{\text {tire }}$ & Tire radius & (m) \\
\hline $\mathrm{t}$ & time & (s) \\
\hline $\mathrm{t}_{0}$ & Failure free time & (h) \\
\hline$t_{\mathrm{EM}}$ & EM time constant & (s) \\
\hline$t_{\text {ICE }}$ & ICE time constant & (s) \\
\hline $\mathrm{T}_{\text {cycle }}$ & Cycle duration & (s) \\
\hline $\mathrm{T}_{\mathrm{act}, \mathrm{EM}}$ & Acting EM torque & $(\mathrm{N} \cdot \mathrm{m})$ \\
\hline $\mathrm{T}_{\text {act,ICE }}$ & Acting ICE torque & $(\mathrm{N} \cdot \mathrm{m})$ \\
\hline $\mathrm{T}_{\mathrm{act}, \mathrm{MB}}$ & Acting $\mathrm{MB}$ torque & $(\mathrm{N} \cdot \mathrm{m})$ \\
\hline $\mathrm{T}_{\mathrm{dem}, \mathrm{brk}}$ & Demanded deceleration torque & $(\mathrm{N} \cdot \mathrm{m})$ \\
\hline $\mathrm{T}_{\text {des, EM }}$ & Desired EM torque & $(\mathrm{N} \cdot \mathrm{m})$ \\
\hline $\mathrm{T}_{\mathrm{des}}$ ICE & Desired ICE torque & $(\mathrm{N} \cdot \mathrm{m})$ \\
\hline $\mathrm{T}_{\mathrm{des}, \mathrm{MB}}$ & Desired $\mathrm{MB}$ torque & $(\mathrm{N} \cdot \mathrm{m})$ \\
\hline $\mathrm{T}_{\text {drag }}$ & Equivalent driving resistance torque & $(\mathrm{N} \cdot \mathrm{m})$ \\
\hline $\mathrm{T}_{\mathrm{G}}$ & Gear torque & $(\mathrm{N} \cdot \mathrm{m})$ \\
\hline
\end{tabular}


$\begin{array}{lll}\mathrm{T}_{\mathrm{i}} & \text { Torque } \mathrm{i} & (\mathrm{N} \cdot \mathrm{m})\end{array}$

$\mathrm{T}_{\text {max,EM,ICE }}$ Sum of maximum EM generator and ICE drag torque $\quad(\mathrm{N} \cdot \mathrm{m})$

$\mathrm{T}_{\max }$ ICE Maximum ICE drag torque (N.m)

$\mathrm{T}_{\mathrm{j}} \quad$ Characteristic lifetime of a single bearing $\mathrm{j} \quad(\mathrm{h})$

vact Actual velocity $\left(\mathrm{km} \cdot \mathrm{h}^{-1}\right)$

$\begin{array}{ll}\mathrm{v}_{\text {des }} \quad \text { Desired velocity } & \left(\mathrm{km} \cdot \mathrm{h}^{-1}\right)\end{array}$

$\mathrm{x}_{\mathrm{brk}} \quad$ Brake pedal position

$\mathrm{x}_{\mathrm{thr}} \quad$ Throttle pedal position

$\dot{\mathrm{x}}_{\mathrm{veh}} \quad$ Vehicle velocity $\quad\left(\mathrm{km} \cdot \mathrm{h}^{-1}\right)$

$\mathrm{X} \quad$ dynamic radial load factor

Y dynamic axial load factor $\quad$ (1)

\section{Appendix A}

Table A1. Bearing parameters. Position according to Figure 2. Dynamic load rating $\mathrm{C}$ and mean diameter $\mathrm{d}_{\mathrm{m}}$.

\begin{tabular}{cccc}
\hline Position & Type & $\mathbf{C}(\mathbf{N})$ & $\mathbf{d}_{\mathbf{m}}(\mathbf{m m})$ \\
\hline 1,2 & tapered roller bearing & 64,000 & 65 \\
3 & axial needle roller bearing & 30,000 & 65 \\
4 & needle roller bearing & 26,500 & 30 \\
5 & needle roller bearing & 27,500 & 36 \\
$6,15,17$ & ball bearing & 32,000 & 49.5 \\
7 & cylindrical roller bearing & 33,500 & 53.3 \\
8 & needle roller bearing & 33,500 & 45.5 \\
9 & needle roller bearing & 33,500 & 45.5 \\
10 & needle roller bearing & 33,500 & 45.5 \\
11 & needle roller bearing & 33,500 & 45.5 \\
12 & needle roller bearing & 33,500 & 45.5 \\
13 & needle roller bearing & 33,500 & 45.5 \\
14 & needle roller bearing & 33,500 & 37 \\
16 & cylindrical roller bearing & 59,000 & 53.9 \\
18 & cylindrical roller bearing & 33,500 & 56 \\
19,20 & cylindrical roller bearing & 28,500 & 29.5 \\
\hline
\end{tabular}

Table A2. Total gear ratios $\mathrm{i}_{\mathrm{G}}$ of the transmission.

\begin{tabular}{cc}
\hline Gear & Value \\
\hline 1 & 14.07 \\
2 & 7.66 \\
3 & 4.68 \\
4 & 3.26 \\
5 & 2.52 \\
6 & 2.04 \\
\hline
\end{tabular}

Table A3. Coefficients of driving resistance.

\begin{tabular}{cc}
\hline Parameter & Value and Unit \\
\hline $\mathrm{f}_{\mathrm{d} 0}$ & $160 \mathrm{~N}$ \\
$\mathrm{f}_{\mathrm{d} 1}$ & $4 \mathrm{~N} \cdot \mathrm{s} \cdot \mathrm{m}^{-1}$ \\
$\mathrm{f}_{\mathrm{d} 2}$ & $0.37 \mathrm{~N} \cdot \mathrm{s}^{2} \cdot \mathrm{m}^{-2}$ \\
\hline
\end{tabular}


Table A4. Parameters of the torsional vibration model.

\begin{tabular}{cc}
\hline Parameter & Value and Unit \\
\hline $\mathrm{r}_{\text {tire }}$ & $0.302 \mathrm{~m}$ \\
$\mathrm{~J}_{\text {Veh }}$ & $72.96 \mathrm{~kg} \cdot \mathrm{m}^{2}$ \\
$\mathrm{~J}_{\text {ICE }}$ & $0.3 \mathrm{~kg} \cdot \mathrm{m}^{2}$ \\
$\mathrm{~J}_{\mathrm{DMF}}$ & $0.3 \mathrm{~kg} \cdot \mathrm{m}^{2}$ \\
$\mathrm{~J}_{\mathrm{EE}}$ & $0.2 \mathrm{~kg} \cdot \mathrm{m}^{2}$ \\
$\mathrm{~J}_{\text {Wheel }}$ & $0.5 \mathrm{~kg} \cdot \mathrm{m}^{2}$ \\
$\mathrm{c}_{\mathrm{DMF}}$ & $580 \mathrm{~N} \cdot \mathrm{m} \cdot \mathrm{rad}^{-1}$ \\
$\mathrm{~d}_{\mathrm{DMF}}$ & $50 \mathrm{~N} \cdot \mathrm{m} \cdot \mathrm{s} \cdot \mathrm{rad}^{-1}$ \\
$\mathrm{c}_{\text {shaft, }}$ & $1.1 \mathrm{E} 4 \mathrm{~N} \cdot \mathrm{m} \cdot \mathrm{rad}^{-1}$ \\
$\mathrm{c}_{\text {shaft,r }}$ & $9.5 \mathrm{E} 3 \mathrm{~N} \cdot \mathrm{m} \cdot \mathrm{rad}^{-1}$ \\
$\mathrm{~d}_{\text {shaft }, 1}$ & $6 \mathrm{~N} \cdot \mathrm{m} \cdot \mathrm{s} \cdot \mathrm{rad}^{-1}$ \\
$\mathrm{~d}_{\text {shaft, }}$ & $6 \mathrm{~N} \cdot \mathrm{m} \cdot \mathrm{s} \cdot \mathrm{rad}^{-1}$ \\
$\mathrm{c}_{\text {tire }}$ & $2.3 \mathrm{E} 4 \mathrm{~N} \cdot \mathrm{m} \cdot \mathrm{rad}^{-1}$ \\
$\mathrm{~d}_{\text {tire }}$ & $1.15 \mathrm{~N} \cdot \mathrm{m} \cdot \mathrm{s} \cdot \mathrm{rad}^{-1}$ \\
\hline
\end{tabular}

Table A5. Properties of the WLTC Class 3 cycle.

\begin{tabular}{cc}
\hline Parameter & Value and Unit \\
\hline Duration $\mathrm{T}_{\text {cycle }}$ & $1800 \mathrm{~s}$ \\
Distance & $23,266 \mathrm{~m}$ \\
Average velocity & $46.5 \mathrm{~km} \cdot \mathrm{h}^{-1}$ \\
Maximum velocity & $131 \mathrm{~km} \cdot \mathrm{h}^{-1}$ \\
\hline
\end{tabular}

\section{References}

1. Liu, Z.; Ivanco, A.; Filipi, Z.S. Impacts of real-world driving and driver aggressiveness on fuel consumption of $48 \mathrm{~V}$ mild hybrid vehicle. SAE Int. J. Altern. Power. 2016, 5, 249-258. [CrossRef]

2. Joud, L.; Da Silva, R.; Chrenko, D.; Kéromnès, A.; Le Moyne, L. Smart energy management for series hybrid electric vehicles based on driver habits recognition and prediction. Energies 2020, 13, 2954. [CrossRef]

3. Mock, P. European vehicle market statistics: Pocketbook 2018/2019. Available online: https://theicct.org/sites/ default/files/publications/ICCT_Pocketbook_2018_Final_20190408.pdf (accessed on 18 August 2020).

4. Ehsani, M.; Gao, Y.; Gay, S.E.; Emadi, A. Modern Electric, Hybrid Electric, and Fuel Cell Vehicles. Fundamentals, Theory, and Design; CRC Press: Boca Raton, FL, USA, 2005; ISBN 0-8493-3154-4.

5. Guercioni, G.R.; Vigliani, A. Gearshift control strategies for hybrid electric vehicles: A comparison of powertrains equipped with automated manual transmissions and dual-clutch transmissions. Proc. Inst. Mech. Eng. Part D J. Automob. Eng. 2019, 233, 2761-2779. [CrossRef]

6. Fischer, R.; Küçükay, F.; Jürgens, G.; Najork, R.; Pollak, B. The Automotive Transmission Book; Springer International Publishing: Cham, Germany, 2015; ISBN 978-3-319-05262-5.

7. Sieg, C.; Küçükay, F. Benchmarking of dedicated hybrid transmissions. Vehicles 2020, 2, 6. [CrossRef]

8. Foulard, S. Online and Real-Time Load Monitoring for Remaining Service Life Prediction of Automotive Transmissions: Damage Level Estimation of Transmission Components Based on a Torque Acquisition; Darmstadt University of Technology: Darmstadt, Germany; Shaker: Aachen, Germany, 2015; ISBN 9783844039504.

9. Winner, H. Challenges of automotive systems engineering for industry and academia. In Automotive Systems Engineering; Maurer, M., Winner, H., Eds.; Springer: Berlin/Heidelberg, Germany, 2013; pp. 3-15.

10. Bertsche, B.; Göhner, P.; Jensen, U.; Schinköthe, W.; Wunderlich, H.-J. Zuverlässigkeit mechatronischer Systeme. Grundlagen und Bewertung in Frühen Entwicklungsphasen; Springer: Berlin/Heidelberg, Germany, 2009; ISBN 978-3-540-85089-2.

11. Leopold, T. Ganzheitliche Datenerfassung für verbesserte Zuverlässigkeitsanalysen. Ph.D. Thesis, University of Stuttgart, Stuttgart, Germany, 2012.

12. Xue, X.; Guo, R.; He Esq, J.; Hong, Z. A road load data processing method for transmission durability optimization development. In Proceedings of the WCX SAE World Congress Experience, Washington, DC, USA, 21-23 April 2020. [CrossRef] 
13. Müller-Kose, J.-P. Repräsentative Lastkollektive für Fahrzeuggetriebe; Technical University of Braunschweig: Braunschweig, Germany; Shaker: Aachen, Germany, 2002; ISBN 3832210032.

14. Kücükay, F.; Kassel, T.; Eghtessad, M.; Kollmer, H. Requirement Engineering Using the 3D Method; SAE International: Warrendale, PA, USA, 2011.

15. Belingardi, G.; Cuffaro, V.; Curà, F. Dynamic additional loads influencing the fatigue life of gears in an electric vehicle transmission. Frat. Integrità Strutt. 2014, 8, 469-477. [CrossRef]

16. Kamper, T.; Hwang, D.H.; Juretzki, B.; Neumann, S.; Wöll, L. Comprehensive reliability model of a passenger car gearbox. In Proceedings of the Tagungsband Antriebstechnisches Kolloquium ATK 2017, Aachen, Germany, 7-8 March 2017; ISBN 978-3-7431-4897-0.

17. Foulard, S.; Rinderknecht, S.; Ichchou, M.; Perret-Liaudet, J. Automotive drivetrain model for transmission damage prediction. Mechatron 2015, 30, 27-54. [CrossRef]

18. Foulard, S.; Ichchou, M.; Rinderknecht, S.; Perret-Liaudet, J. Online and real-time monitoring system for remaining service life estimation of automotive transmissions-Application to a manual transmission. Mechatronics 2015, 30, 140-157. [CrossRef]

19. Foulard, S.; Rinderknecht, S.; Fietzek, R. Lightweight design of automotive transmissions through online and real-time lifetime monitoring. ATZ Worldw. 2016, 118, 72-77. [CrossRef]

20. Rinderknecht, S.; Fietzek, R.; Foulard, S. Online and real-time condition prediction for transmissions based on CAN-signals. In Proceedings of the WCX ${ }^{\mathrm{TM}}$ 17: SAE World Congress Experience, Detroit, MI, USA, 4 April 2017.

21. Haq, S.; Joseph, B.; Lee, Y.-L.; Taylor, D.; Attibele, P. Vehicle powertrain loading simulation and variability. J. Mater. Manuf. 2004, 113, 751-756. [CrossRef]

22. Friedmann, M.; Kollmeier, H.-P.; Gindele, J.; Schmid, J.M. Synthetic driving cycles in the area of powertrain testing. ATZ Worldw. 2015, 117, 40-45. [CrossRef]

23. Fugel, M.; Scholz, N.; Kücükay, F. Anforderungen an die Getriebe in Hybridantrieben. In Proceedings of the Getriebe in Fahrzeugen 2006, Friedrichshafen, Germany, 27-28 June 2006; ISBN 3-18-091943-4.

24. Lavall, T. The "Hybrid Effect": Influence of hybridisation on the durability of automatic transmissions. In Proceedings of the Getriebe in Fahrzeugen 2009, Friedrichshafen, Germany, 30-31 July 2009; pp. 661-672, ISBN 9783180920719.

25. Kurtzke, A.; Hierlwimmer, P. CAE-basierte abstimmung bezüglich des fahrzeug-leistungsverhaltens und der getriebelebensdauer. In Proceedings of the 7. Fachtagung Dynamisches Gesamtsystemverhalten von Fahrzeugantrieben, Munich, Germany, 10-11 March 2009; ISBN 9783816928447.

26. Naunheimer, H.; Bertsche, B.; Ryborz, J.; Novak, W. Automotive Transmissions. Fundamentals, Selection, Design and Application; Springer: Berlin/Heidelberg, Germany, 2011; ISBN 978-3-642-16213-8.

27. Commission of the European Communities. Regulation (EEC) No 4064/89 Merger Procedure. 1999. Available online: https://ec.europa.eu/competition/mergers/cases/decisions/m1406_en.pdf (accessed on 18 August 2020).

28. Wöll, L.; Feldermann, A.; Jacobs, G. Sensitivity analysis on the reliability of an offshore winch regarding selected gearbox parameters. MIC 2017, 38, 51-58. [CrossRef]

29. Neumann, S.; Wöll, L.; Feldermann, A.; Strassburger, F.; Jacobs, G. Modular system modeling for quantitative reliability evaluation of technical systems. MIC 2016, 37, 19-29. [CrossRef]

30. ISO International Organization for Standardization. Rolling Bearings_Dynamic Load Ratings and Rating Life (ISO 281); ISO International Organization for Standardization: Zurich, Switzerland, 2007.

31. Köhler, M.; Jenne, S.; Pötter, K.; Zenner, H. Load Assumption for Fatigue Design of Structures and Components. Counting Methods, Safety Aspects, Practical Application; Springer: Berlin/Heidelberg, Germany, 2017; ISBN 978-3-642-55248-9.

32. Bertsche, B.; Lechner, G. Reliability in Automotive and Mechanical Engineering; Springer: Berlin/Heidelberg, Germany, 2008; ISBN 978-3-540-33969-4.

33. Keller, M.; Schmitt, L.; Abel, D. Nonlinear hierarchical model predictive control for the energy management of a hybrid electric vehicle. In Proceedings of the 2019 27th Mediterranean Conference on Control and Automation (MED), Akko, Israel, 1-4 July 2019; pp. 451-456. [CrossRef]

34. Habermehl, C.; Kramer, A.; Jacobs, G. Interconnected drivetrain development in a physical and virtual environment. ATZ Worldw. 2019, 121, 78-83. [CrossRef]

35. Habermehl, C.; Jacobs, G.; Neumann, S. A modeling method for gear transmission efficiency in transient operating conditions. Mech. Mach. Theory 2020, 153, 103996. [CrossRef] 
36. United Nations Economic Commission for Europe. Global Technical Regulation No. 15. Worldwide harmonized Light vehicles Test Procedure. ECE/TRANS/180, 2014. Available online: https://www.unece.org/ trans/main/wp29/wp29wgs/wp29gen/wp29glob_registry.html (accessed on 18 August 2020).

37. Naunheimer, H.; Bertsche, B.; Ryborz, J.; Novak, W.; Fietkau, P. Fahrzeuggetriebe; Springer: Berlin/Heidelberg, Germany, 2019; ISBN 978-3-662-58882-6.

38. Malik, R.; Masur, E.; Schick, A. Bearings and bearing design for transmissions. Encyclopedia Automot. Eng. 2014, 1, 1-15. [CrossRef]

39. Chen, Y.; Li, K.; Zang, L.; Zheng, Y.; Jia, S.; Zhou, H.; Yu, M.; Xue, B. Analysis on contact strength of needle roller bearing of transmission and effect of surface modification. In Proceedings of China SAE Congress 2018: Selected Papers; Springer: Singapore, 2020; pp. 879-891; ISBN 978-981-13-9717-2.

40. Kubaisi, R.; Herold, K.; Gauterin, F.; Giessler, M. Regenerative braking systems for electric driven vehicles: Potential analysis and concept of an adaptive system. In Proceedings of the SAE 2013 Brake Colloquium $\mathcal{E}$ Exhibition-31st Annual; SAE International: Warrendale, PA, USA, 2013.

41. Solberg, G. The Magic of Tesla Roadster Regenerative Braking. Available online: https://www.tesla.com/ blog/magic-tesla-roadster-regenerative-braking (accessed on 18 August 2020).

(C) 2020 by the authors. Licensee MDPI, Basel, Switzerland. This article is an open access article distributed under the terms and conditions of the Creative Commons Attribution (CC BY) license (http://creativecommons.org/licenses/by/4.0/). 